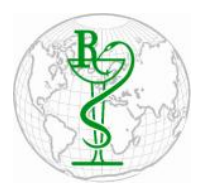

INDO GLOBAL JOURNAL OF

PHARMACEUTICAL SCIENCES

ISSN 2249- 1023

\title{
Recent Advances in Pyrazoline Derivatives: A Review
}

\author{
Himangini Bansal ${ }^{*}$, D.P. Pathak \\ Department of Pharmaceutical Chemistry, Delhi Institute of Pharmaceutical Science \& Research, New Delhi-17, India
}

\begin{abstract}
Address for Correspondance Himangini Bansal, $\underline{\text { himanginibansal }}$ @gmail.com
\end{abstract}

Keywords Pyrazoline; Synthesis; Anticancer; Chalcone.

\begin{abstract}
Pyrazolines and its fused heterocyclic derivatives tested with diverse pharmacological activity constitute an important class of compounds for new drug development. The synthesis of novel pyrazoline derivatives and investigation of their chemical and biological behavior have gained more importance in recent decades. So far, modifications of the pyrazoline ring have proven highly effective with improved potency and lesser toxicity. The present review provides an in depth view of work done so far on pyrazoline and its biological activities covering anticancer, antimycobacterial, antimicrobial, anticonvulsant, antiinflamatory and cardiovascular activities.(C 2015 iGlobal Research and Publishing Foundation. All rights reserved.
\end{abstract}

\section{INTRODUCTION}

Diversely substituted pyrazolines and their derivative embedded with variety of functional groups are important biological agents and a significant amount of research activity has been directed towards this class. The 2-pyrazolines were synthesized by the reaction of appropriate chalcone derivative and hydrazine hydrate according to the condensation reaction of $\alpha, \beta$-unsaturated ketones with hydrazines. They possess antitumur, antidepressant, anticovulsant, hyperglycemic, malarial, antimicrobial and antituberculosis and. Some of these compounds have potent selective activity such as MAO inhibitors, COX-II inhibitors and Cannabinoid CB1 and CB2 receptor antagonists activity. On the other hand, 1,2,3-triazoles have received much attention due to their interesting bioactivity profile such as anti-biotic, anti-fungal, anti-cancer, anti-HIV, anti-microbial, etc. properties. Also, they serve as potential chemotherapeutic agents for various diseases [1]. So far, modifications of the pyrazoline ring have proven highly effective with improved potency and lesser toxicity. The preceding section of the review is focusing on the recent development on pyrazolines along with their biological properties.

\section{BIOLOGICAL ACTIVITIES OF PYRAZOLINES}

\section{Anticancer activity}

Zhi hui lu et al furished a new series of pyrazoline analogs and evaluated for their in vitro anticancer efficacies against human non-small-cell lung cancer cell line A549. $\alpha$-Naphthyl isothiocyanate was prepared from benzoyl chloride and anaphthyl amine through $\alpha$-naphthyl thiourea to react with pyrazoline intermediates $\mathbf{1}$ in good yields and purity. Final compounds revealed that analogs with fluorine and thiomethyl and methoxy functional group demonstrated good potencies against A549 cell lines with reasonable level of cytotoxic nature.[2] Ya juan quin et al designed and synthesized pyrazoline derivatives. Among them, compound 2 displayed the most potent antiproliferative activity against A549, MCF-7 and HepG-2 cells line (IC50 1/4 $0.07 \mathrm{mM}, 0.05 \mathrm{mM}, 0.03 \mathrm{mM}$, respectively) and the tubulin polymerization inhibitory activity (IC50 $1 / 41.88 \mathrm{mM}$ ). This compound was a potent inducer of apoptosis in HepG-2 cells and it had cellular effects typical for microtubule interacting agents, causing accumulation of cells in the G2/M phase of the cell cycle. [3] 


\section{Indo Global Journal of Pharmaceutical Sciences, 2016; 6(1): 1-13}

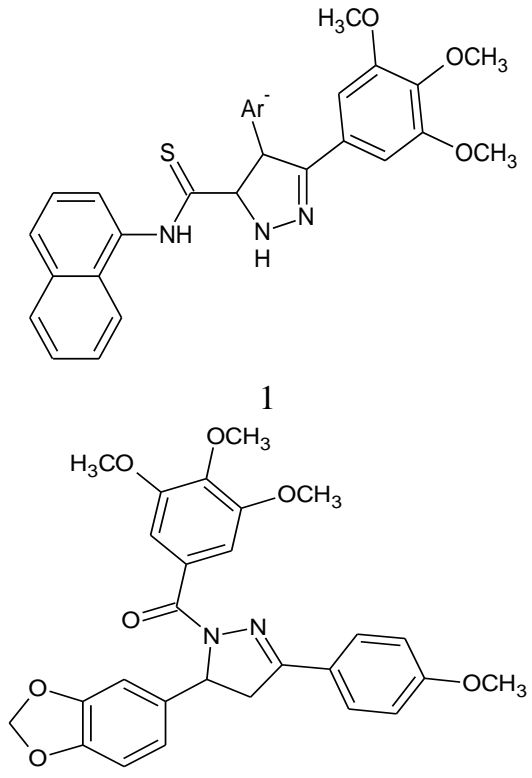

2

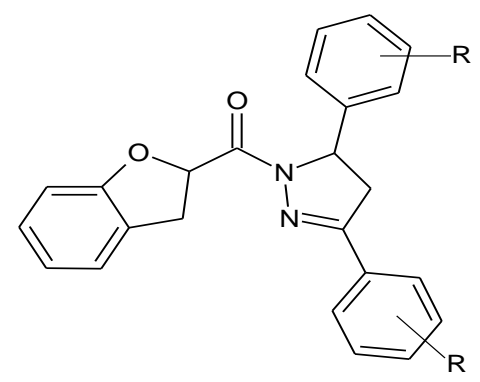

3

Shrey Parekh et al descried a new series of benzofuran-2yl(4,5-diydro-3,5-substituted-diphenylpyrazol-1-yl)

methanone 3 derivatives by the reaction of the benzofuran-2carbohydrazides with various chalcone derivatives using microwave irradiation. The effect of synthesized compounds showed good antiproliferative activity against human cancer cell lines and exhibited good reversal activity of multidrug resistance on human MDR1-gene transfected mouse lymphoma cells.[4] Pyrazoline containing phenothiazine ring was designed and synthesized by Lavinia Baciu-Atudosie et al. Compounds 4 was the most active against protein farnesyltransferase and growth of HCT-116, LOX IMVI and SK-MEL-5 cell lines.[5] Rafia bashir et al reported 1,3,5 trisubstituted pyrazolines bearing benzene sulphoamide 5 with considerable antitumor activities and growth inhibition GI50.[6] Pooja Rathore et al. designed and synthesized some new pyrazoline substituted benzenesulfonylureas derivatives 6 and tested for anticancer activity.[7]
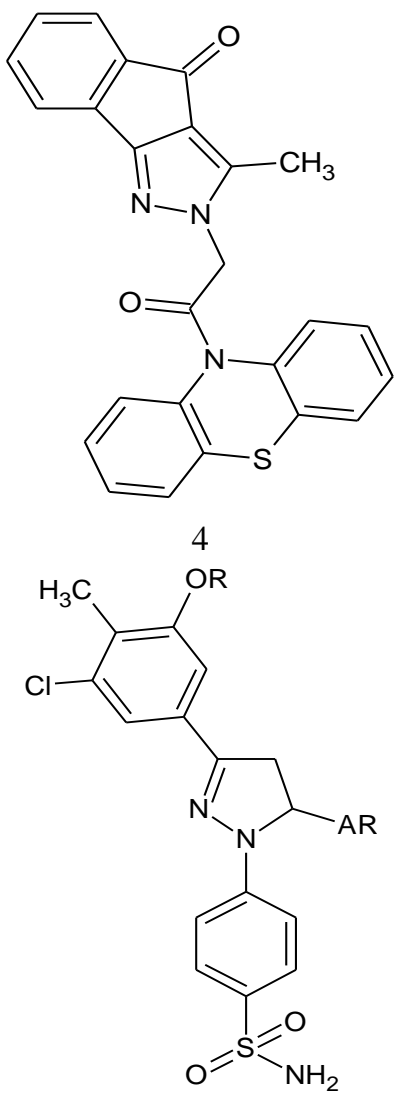

5

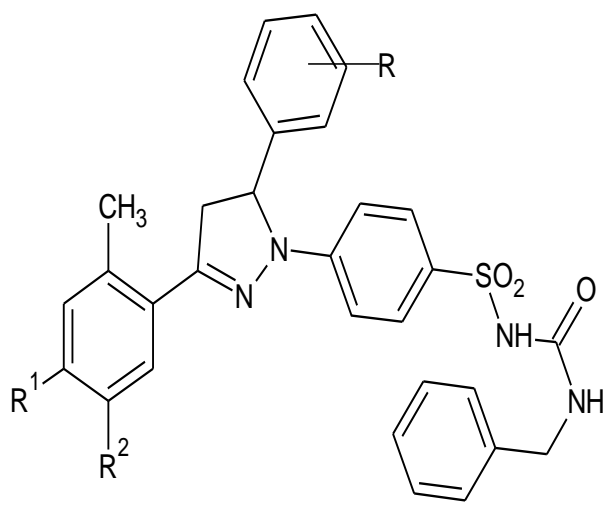

6

Kamilia M Amin et al designed and synthesised coumarin derivatives $\mathbf{7}$ bearing diversely substituted pyrazoline moieties. Cytotoxicity of the synthesized compounds was evaluated in vitro against liver HepG2 cell line. The most active compounds were investigated for their telomerase inhibition and proapoptotic activities. [8] A series of pyrazolyl-thiazolinone derivatives had been designed and synthesized and evaluated as potential EGFR and HER-2 kinase inhibitors. Compound 2-(5-(4-bromophenyl)-3-p-tolyl4,5-dihydro-1H-pyrazol-1-yl)thiazol-4(5H)-one $\mathbf{8}$ displayed the most potent inhibitory activity against MCF-7, B16-F10 and HCT-116 in vitro, with IC50 value of $0.30,0.54$, and 0.70 $\mu \mathrm{M}$, respectively.[9] 


\section{Indo Global Journal of Pharmaceutical Sciences, 2016; 6(1): 1-13}<smiles>COc1ccc2ccc(=O)oc2c1C1=NN(P)C(C(C)C)C1</smiles>

7<smiles>Cc1ccc(C2=NN(C3=NC(=O)CS3)C(c3ccc(Br)cc3)C2)cc1</smiles>

8<smiles>[R7]c1ccc(C2=NN(c3nc(-c4ccccc4)c(C#N)c(=O)n3C)C(c3ccc(P)cc3)C2)cc1</smiles>

9<smiles>[R7]c1ccc(C2=NN(c3nc(-c4ccc(Cl)cc4)c(C#N)c(=O)n3C)C(c3ccc([R7])cc3)C2)cc1</smiles>

10

Fadi M Awadallah et al synthesized two series of 2-(3,5diaryl-4,5-dihydropyrazol-1-yl)-1-methyl-6-oxo-4-phenyl-1,6dihydropyrimidine-5-carbonitriles 9 and 4-(4-chlorophenyl)-2(3,5-diaryl-4,5-dihydropyrazol-1-yl)-1-methyl-6-oxo-1,6dihydropyrimidine-5-carbonitriles $\mathbf{1 0}$ and screened for their antiproliferative activity against A 549 (lung), HT 29 (colon), MCF 7 and MDA-MB 231 (breast) cell lines. The 4unsubstitutedphenylpyrimidine derivatives were more active than their 4-chlorophenylpyrimidine analogs.[10] PengCheng Lv et al reported thiazolyl-pyrazoline derivatives and screened for their EGFR kinase inhibitory activity. Compound 4-(4-chlorophenyl)-2-(3-(3,4-dimethylphenyl)-5-p-tolyl-4,5dihydro-1H-pyrazol-1-yl)thiazole 11 displayed the most potent EGFR TK inhibitory activity with $\mathrm{IC}_{50}$ of $0.06 \mu \mathrm{M}$. Molecular docking results indicated that compound 11 was nicely bound to the EGFR kinase and showed significant antiproliferative activity against MCF-7 with $\mathrm{IC}_{50}$ of $0.07 \mu \mathrm{M}$, which would be a potential anticancer agent.[11]
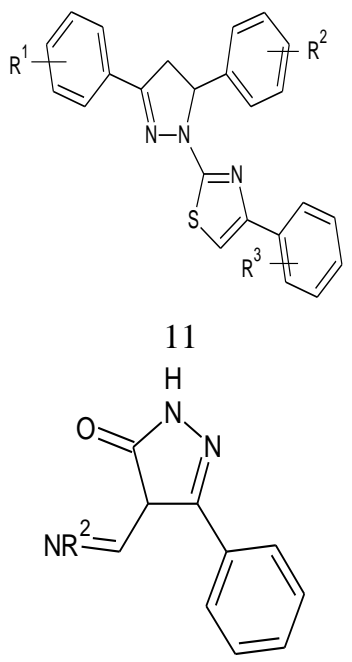

12<smiles>[NH2+]=CC1C(=O)N(c2ccccc2)N=C1c1ccccc1</smiles>

13
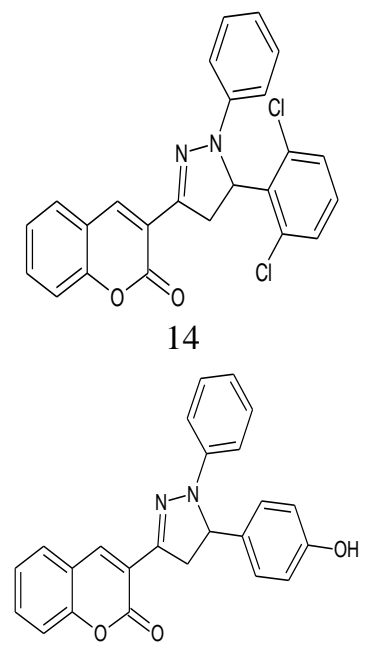

15

4-aminomethylidene derivatives obtained from 3-phenyl-2pyrazolin-5-one 12 and 1,3-diphenyl-2-pyrazolin-5-one $\mathbf{1 3}$ were synthesized and tested for their antiproliferative activity against human breast cancer MDA-MB-361 and MDA-MB453 cell lines. The compounds derived from 1,3-diphenyl-2pyrazolin-5-one exhibited the most remarkable activity in the treatment of both cell lines.[12] Nitin kumar et al prepared a novel series of 3-(4, 5-dihydro-1-phenyl-5-substituted phenyl1H-pyrazol-3-yl)-2Hchromen-2-one derivatives and tested for anti cancer activity. It was observed that simple coumarin ring derivatives were more effective in inhibiting the growth of 


\section{Indo Global Journal of Pharmaceutical Sciences, 2016; 6(1): 1-13}

cancerous cell lines, than coumarin-pyrazoline derivatives. Among all the synthesized compounds, irrespective of compounds having simple coumarin ring and coumarinpyrazoline combination, compounds $\mathbf{1 4}$ and $\mathbf{1 5}$ were potent anticancer agents [13]. Kamilia $\mathrm{M}$ amin et al sythesised two groups of coumarine-pyrazoline hybrids and investigated for their anticancer activity toward 60 cancer cell lines according to US NCI protocol where breast cancer MCF7 and colon cancer HCT-116 were the most susceptible to the influence of compounds 16, 17 and 18. The tested compounds exhibited high potency with $\mathrm{IC}_{50}$ ranging from $0.01 \mathrm{mM}$ to $2.8 \mathrm{mM}$. [14]
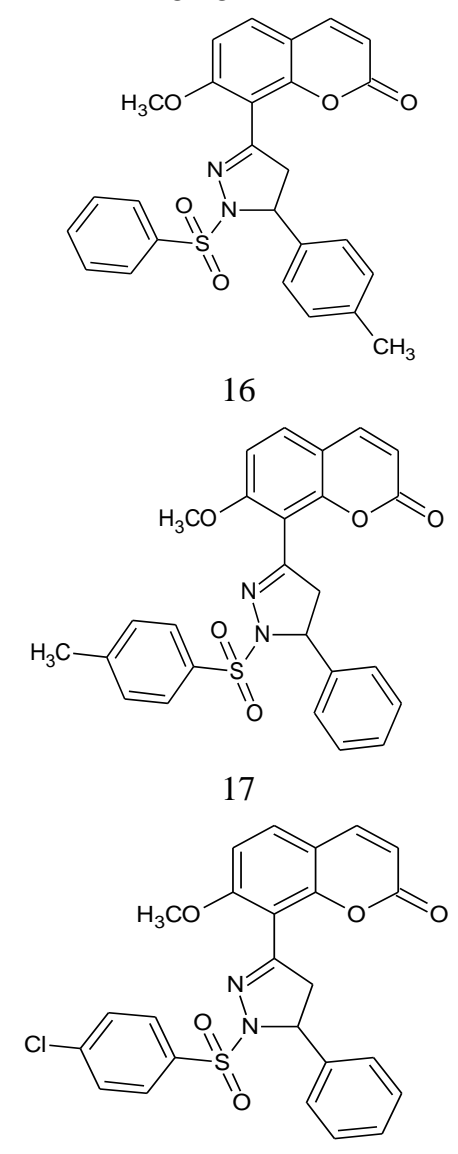

18

\section{Antidepressant and Anticonvulsant activity}

Pravin O patil et al synthesized a series of new substituted 5(1H-Indol-3-yl)-3-(phenyl)-4,5-dihydropyrazoline derivatives 19 with good yield with the help of microwave and screened for antidepressant and anticonvulsant potentialities. The results revealed that few compounds were found to be potent antidepressant molecules whereas, few showed potent anticonvulsant activity when compared with the reference drug.[15] Carboxamide and carbothioamide derivatives of 2pyrazolines were reported by Nagihan beyhan et al and found to be more potent due to their ability to form strong hydrogen bonds and their hydrophobic nature. Furthermore, the carboxamide derivatives of $\mathbf{2 0}$ and $\mathbf{2 1}$ were much more potent
( $90 \%$ protection) in PTZ test because of the bulk they own and their lipophilicity.[16]<smiles>[R11]C1=NN(c2ccccc2)C(c2c[nH]c3ccc([R])cc23)C1</smiles>

19<smiles>O=C(Nc1ccc(Cl)cc1)N1N=C(c2ccc(Br)s2)CC1c1c(Cl)cccc1Cl</smiles>

20<smiles>O=C(Nc1ccc(Cl)cc1)N1N=C(c2ccc(Cl)s2)CC1c1c(Cl)cccc1Cl</smiles>

21

Nikhil D. Amnerkar et al designed a series of 6-substituted-[3substituted-prop-2-eneamido] benzothiazole and 6-substituted2-[(1-acetyl-5-substituted)-2-pyrazolin-3-yl]

aminobenzothiazole and evaluated against maximal electroshock test. The most active compound, 22 exhibited an $\mathrm{ED}_{50}$ of $25.49 \mathrm{mmol} / \mathrm{kg}, \mathrm{TD}_{50}$ of $123.8 \mathrm{mmol} / \mathrm{kg}$ and high protective index (PI) of 4.86 compared to standard drug phenytoin.[17]. Some triazolo-pyrazoline derivatives 23 were synthesized to investigate their potential antidepressant activities. The test compounds in the series exhibited different levels of antidepressant activities when compared to reference drug fluoxetine. [18] 
<smiles>[R7]c1ccc(C2CC(c3cccs3)=NN2C(=O)CSc2nnc(CCc3ccc(O)cc3)n2N)cc1[R]</smiles>

23

\section{Cannabinoid receptor antagonist}

Vincent Gembus et al established a new class of C4-benzyl pyrazolines 24 with the use of a resin base reagent strategy having significant $\mathrm{CB} 2 / \mathrm{CB} 1$ selectivity in favor of $\mathrm{CB} 2$ receptors, although an agonist behavior was mainly measured.[19] Jos H. M. Lange et al described the structureactivity relationship (SAR) studies and intramolecular hydrogen bonding pattern of synthesized 1,3,5-trisubstituted 4,5-dihydropyrazoles 25 . The target compounds represented a novel class of potent and selective CB1 receptor antagonists.[20]

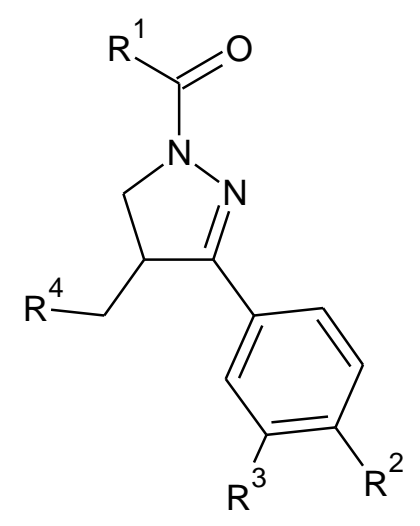

24

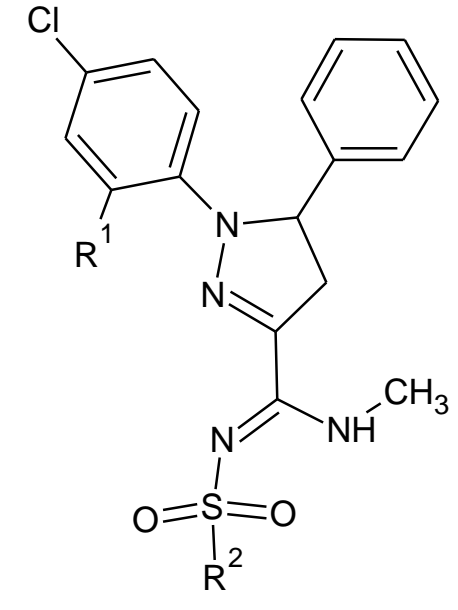

25

\section{COX-2 inhibitor}

Minmin $\mathrm{Yu}$ et al designed pyrazoline derivatives modified from Celecoxib and synthesized as bi-inhibitor of COX-2 and B-Raf. They were evaluated for their COX-1/COX-2/B-Raf inhibitory and anti-proliferation activities. Compound 26 displayed the most potent activity against $\mathrm{COX}-2\left(\mathrm{IC}_{50}=\right.$ $0.008 \mu \mathrm{M})$ and showed superb COX-1/COX-2 selectivity $(>500)$, being more potent and selective than positive control Celecoxib. Compound 27 retained superb bioactivity against $\mathrm{COX}-2\left(\mathrm{IC}_{50}=0.015 \mu \mathrm{M}\right)$.[21] A series of dihydro-pyrazolylthiazolinone derivatives had been synthesized and evaluated as potential cyclooxygenase-2 (COX-2) inhibitors by Ke-Ming Qiu et al. Compound 2-(3-(3,4-dimethylphenyl)-5-phenyl-4,5dihydro-1H-pyrazol-1-yl)thiazol-4(5H)-one 28 displayed the most potent COX-2 inhibitory activity with $\mathrm{IC}_{50}$ of $0.5 \mu \mathrm{M}$, but weak to COX-1.[22] Rossella Fioravanti et al reported new 1-N-substituted-3,5-diphenyl-2-pyrazoline derivatives 29 and cyclooxygenase (COX-1 and COX-2) inhibitory activities had been evaluated. The results showed that all of new derivatives were not endowed with improved antiinflammatory activity against COX-1, but some of them showed a good activity against COX-2. [23]

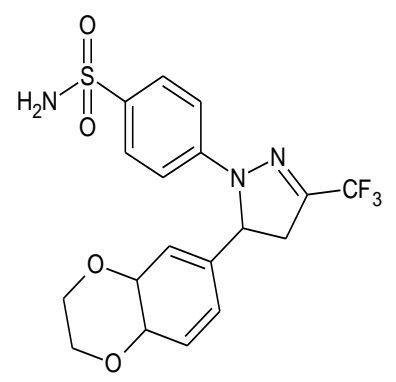

26 


\section{Indo Global Journal of Pharmaceutical Sciences, 2016; 6(1): 1-13 \\ Xanthine oxidase inhibitor}

Deependra Kumar et al designed and synthesized some 5,6dihydropyrazolo/pyrazolo[1,5-c]quinazoline derivatives and evaluated for in vitro xanthine oxidase inhibitory activity. The compounds 31 were found to be the most potent $\mathrm{XO}$ inhibitor as compared to allopurinol and free radical scavenger.[25]

\section{Antihyperglycemic activity}

Manisha R. Bhosle et al reported thiazolylmethoxyphenyl pyrazolines with better yields. Among those compound 32 had displayed noticeable antihyperglycemic activity.[26] Syed Ovais et al synthesized seventeen new pyrazoline substituted benzenesulfonylurea/thiourea derivatives 33. Thirteen compounds showed moderate to good anti-hyperglycaemic activity in glucose fed hyperglycaemic normal rats at the dose of $0.05 \mathrm{mM} / \mathrm{kg}$ body weight. Out of these some compounds were found more effective than the known ARI sorbinil. Five compounds showed significant dual action (antihyperglycaemic and aldose reductase inhibition).[27] Twenty six benzenesulfonylureas containing thiophenylpyrazoline moiety had been synthesized and evaluated for their antidiabetic effect by oral glucose tolerance test. In vitro PPAR- $\gamma$ transactivation assay was performed on active compounds in order to validate docking results and the most active compound 34 was also shown to elevate gene expression of PPAR- $\gamma \cdot[28]$

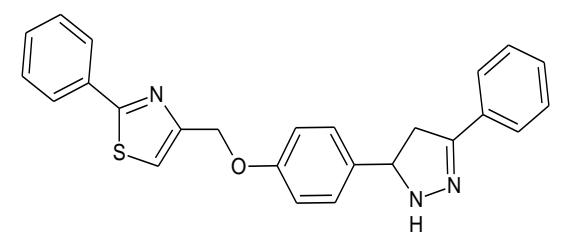

\section{Antihepatotoxic activity}

Habibullah Khalilullah et al synthesized novel pyrazoline derivatives 30 containing 1,4-dioxane ring system from 3-(2,3dihydro-1,4-benzodioxane-6-yl)-1-substituted-phenylprop-2-

en-1-one. Some of the synthesized compounds were evaluated for antihepatotoxic activity against $\mathrm{CCl}_{4}$-induced hepatotoxicity and showed significant antihepatotoxic activity comparable to standard drug silymarin.[24]

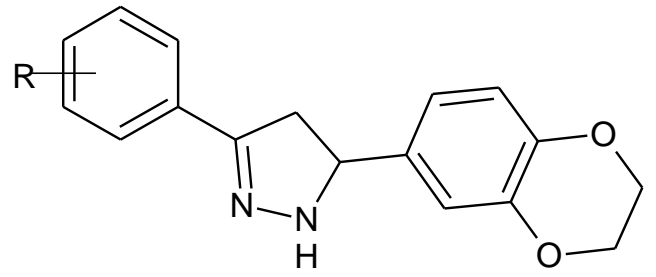

30<smiles>Oc1c(Cl)cc(Cl)cc1C1Nc2ccccc2-c2cc(-c3ccccc3)nn21</smiles>

32

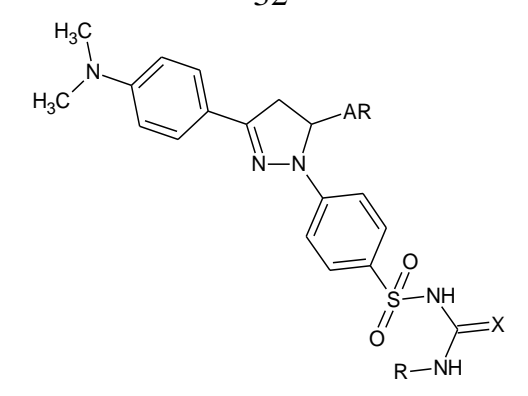

33

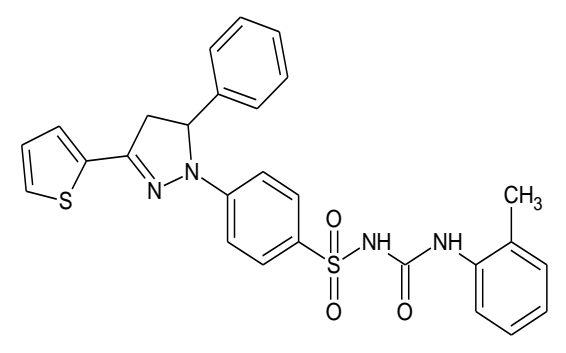

34 


\section{Indo Global Journal of Pharmaceutical Sciences, 2016; 6(1): 1-13}

\section{Antiinflammatory and Analgesic activity}

Shivapura viveka et al synthesized some new substituted pyrazoline derivatives and was screened for their antiinflammatory, analgesic and antibacterial activities. The preliminary results revealed that the $\mathrm{N}$-acylated 35 and nitro substituted N-phenyl 36 pyrazolyl-pyrazolines derivatives exhibited a very promising anti-inflammatory activity whereas both were showing interesting analgesic property.[29] A series of 5-bromo-2-(3,5-diaryl-4,5-dihydro-1H-pyrazol-1yl)pyrimidine 37 were prepared under conventional heating as well as microwave reaction condition. These new compounds were screened for their antioxidant, anti-inflammatory and analgesic activities. Some of these compounds exhibited potent biological activities compared to the standard drug.[30]<smiles>CCC(=O)N1N=C(c2ccc(F)cc2)CC1c1cn(-c2ccccc2)nc1-c1ccc(Cl)c(Cl)c1</smiles>

35<smiles>Cc1ccc(C2=NN(c3ccc([N+](=O)[O-])cc3)C(c3cn(-c4ccccc4)nc3-c3ccc(Cl)c(Cl)c3)C2)cc1</smiles>

36<smiles>[R7]c1ccc(C2=NN(c3ncc(Br)cn3)C(c3ccc(Br)cc3)C2)cc1</smiles>

37
Jiqiang $\mathrm{He}$ et al reported twenty-eight pyrazoline derivatives and evaluated for their inhibitory potency on the production of inflammatory mediator nitric oxide (NO) in LPS-stimulated RAW 264.7 cells. Among them, 38 exhibited potent inhibitory effects on NO production and iNOS activity superior to positive control Indomethacin. Furthermore, it could suppress the progress of carrageenan-induced hind paw edema at a dosage of $50 \mathrm{mg} / \mathrm{kg} /$ day and dose-dependently ameliorate the development of adjuvant-induced arthritis.[31] Chetna Kharbanda et al presented the synthesis of pyrazolines bearing benzothiazole and their evaluation as anti-inflammatory agents. The compound 39 found to be the most potent antiinflammatory agents attributing to the suppression of the COX-2 enzyme activity and TNF- $\alpha$ production without being either cytotoxic or ulcerogenic.[32] A novel series of 3(substituted)-aryl-5-(9-methyl-3-carbazole)-1H-2-pyrazolines had been synthesized and evaluated for their antiinflammatory activity, and for their antioxidant activity by Babasaheb P. Bandgar. Compound 40 was found to be selective COX-2 inhibitors and potent inhibitor of the carrageenin induced paw edema in rats.[33] Magda A.-A. ElSayed et al synthesized new pyrazole and pyrazoline derivatives and their ability to inhibit ovine COX-1/COX-2 isozymes was evaluated using in vitro cyclooxygenase (COX) inhibition assay. Among the tested compounds, N-((5-(4chlorophenyl)-1-phenyl-3-(trifluoromethyl)-1H-pyrazol-4-

yl)methylene)-3,5-bis(trifluoromethyl)aniline 41 exhibit optimal COX-2 inhibitory potency $\left(\mathrm{IC}_{50}=0.26 \mu \mathrm{M}\right)$ and selectivity $(\mathrm{SI})=>192.3$ ] comparable with reference drug celecoxib ( $\mathrm{IC}_{50}$ value of $0.28 \mu \mathrm{M}$ and selectivity index of 178.57).[34] Ranjana Aggarwal et al synthesized a series of novel 2-(5-hydroxy-5-trifluoromethyl-4,5-dihydropyrazol-1yl)-4-(coumarin-3-yl)thiazoles 42 by condensing3-(2bromoacetyl)coumarins withvarious 5-hydroxy-5trifluoromethyl-4,5-dihydropyrazol-1-thiocarboxamides. All the tested compounds displayed significant to moderate in vivo anti-inflammatory activity when compared to the standard drug indomethacin.[35]<smiles>COc1ccc(C2=NN(C(C)=O)C(c3cc(OC)c(OC)c(OC)c3)C2)c2c1C=CC(C)(C)O2</smiles>

38 


\section{Indo Global Journal of Pharmaceutical Sciences, 2016; 6(1): 1-13}

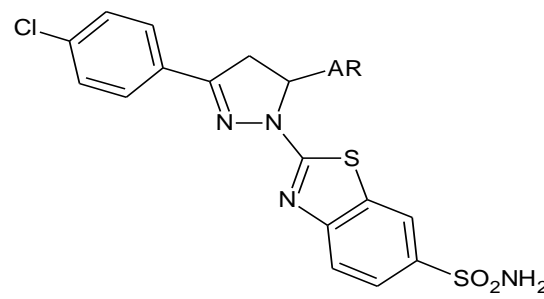

39
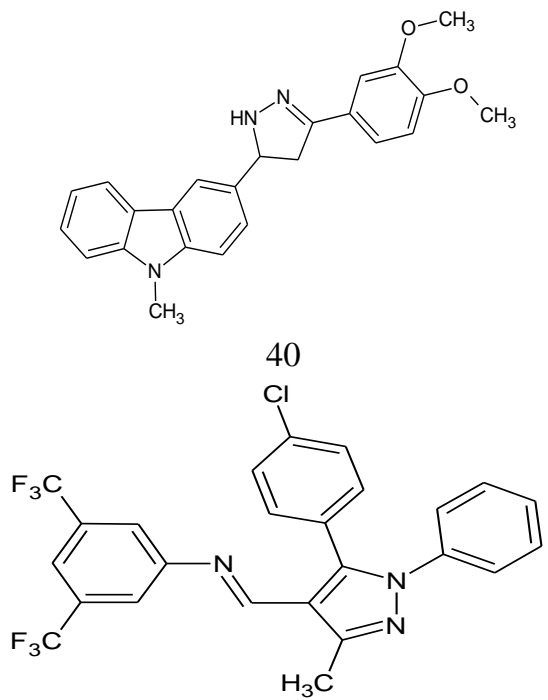

41

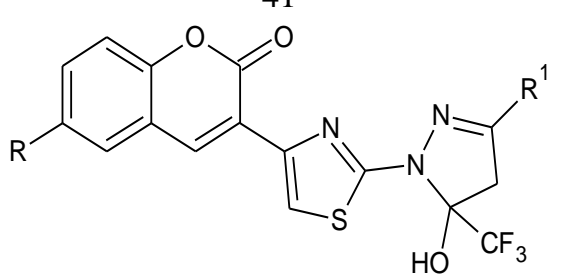

42

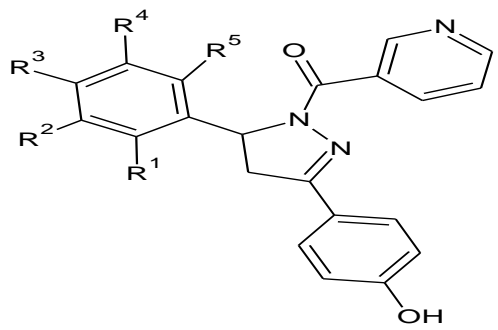

43

\section{Antimalarial activity}

A series of 1,3,5-trisubstituted pyrazolines 43 were synthesized and evaluated for in vitro antimalarial efficacy against chloroquine sensitive (MRC-02) as well as chloroquine resistant (RKL9) strains of Plasmodium falciparum by Badri Narayan Acharya et al. $\beta$-hematin formation inhibition activity (BHIA50) of the pyrazolines were determined and correlated with antimalarial activity. A reasonably good correlation $\left(\mathrm{r}^{1 / 4} 0.62\right)$ was observed between antimalarial activity $\left(\mathrm{IC}_{50}\right)$ and BHIA50. Some of the compounds were showing better antimalarial activity than chloroquine against resistant strain of P. falciparum and were also found active in the in vivo experiment.[36]

\section{Antioxidation property}

Akshay Kumar et al synthesized 2-pyrazolines 44 by the condensation of various substituted chalcones and hydrazine hydrate in the presence of ethanol and screened for antioxidant activity using DPPH radical scavenging method, NO scavenging assay, superoxide radical scavenging assay and hydrogen peroxide radical scavenging assay. All the compounds showed good free radical scavenging activity which is comparable to that of the standard ascorbic acid, out of which ATP-1, ATP-2 and ATP-3 come out to be the best molecules with an $\mathrm{IC}_{50}$ less than $40 \mathrm{mcg} / \mathrm{ml}$.[37] A new series of twenty-one trifluoromethyl-containing (E)-N'-arylidene1H-pyrazole-1-carbohydrazides 45 was synthesized by Helio G. Bonacorso et al and screened for their antioxidant and evaluated by DPPH methods. All compounds showed ability to capture $\mathrm{DPPH}$ free radical for $\mathrm{IC}_{50}$ from 47.57 to 487 $\mathrm{mg} / \mathrm{mL}$.[38] Adithya Adhikari et al prepared a series of 5bromo-2-(3,5-diaryl-4,5-dihydro-1H-pyrazol-1-yl)pyrimidine 46 under conventional heating as well as microwave reaction condition. These new compounds were screened for their antioxidant, anti-inflammatory and analgesic activities. Some of these compounds exhibited potent biological activities compared to the standard drug. [39]<smiles>[R]c1ccc(C2CC(c3ccc(O)c(OC)c3)=NN2)cc1[R]</smiles>

44<smiles>[R7]C([R])=NNC(=O)N1N=C([R7])C[C@@]1(O)C(F)(F)F</smiles>

45<smiles>[R7]c1ccc(C2=NN(c3ncc(Br)cn3)C(c3ccc(Br)cc3)C2)cc1</smiles>
46 


\section{MAO Inhibitors}

Begum Evranos-Aksoz et al synthesized a novel series of 2pyrazoline and investigated for their human monoamine oxidase (hMAO) inhibitory activity. All compounds inhibited the hMAO-A isoform competitively and reversibly. According to the experimental $\mathrm{K}_{\mathrm{i}}$ values, compound 47 , which carries a bromine atom at $\mathrm{R}^{4}$ of the $\mathrm{A}$ ring of the pyrazoline, appeared to be the most selective MAO-A inhibitor.[40] Xu Tong et al designed and synthesized thirty seven novel 2-pyrazoline-1ethanone derivatives and evaluated as selective hMAO inhibitors. Among them, compounds $48\left(\mathrm{IC}_{50}=2.40 \mu \mathrm{M}\right)$ and $49\left(\mathrm{IC}_{50}=2.00 \mu \mathrm{M}\right)$ exhibited best inhibitory activity and selectivity against hMAO-A, surpassing that of the positive control Clorgyline $\left(\mathrm{IC}_{50}=2.76 \mu \mathrm{M}\right)$. Based on selective activity of hMAO-A, SAR analysis showed that the order of $\mathrm{N}_{1}$ substituent contribution was bromo > piperidinyl > morpholinyl > imidazolyl, and compounds with electronwithdrawing substituents (-F, $-\mathrm{Cl})$ at $\mathrm{C} 3$ or $\mathrm{C} 5$ phenyl ring of 2-pyrazoline nucleus dedicated stronger MAO-A inhibitory activity.[41] Ethyl and phenyl carbamate derivatives of pyrazoline were synthesized by B. Vishnu Nayak et al and tested for their MAO inhibitory activity. All the compounds were found to be selective towards MAO-A. Phenyl carbamates were better than ethyl carbamates and displayed the best selectivity index. Compound $50\left(\mathrm{Ki}_{\mathrm{MAO}-\mathrm{A}} ; 4.96 \pm 0.21\right.$ $\mathrm{nM}$ ) was found to be equally potent as that of standard drug, Moclobemide $\left(\mathrm{Ki}_{\text {MAO-A }} ; 5.01 \pm 0.13 \mathrm{nM}\right)$ but with best selectivity index $\left(8.86 \times 10^{5}\right)$.[42] Rossella Fioravanti et al designed and synthesized a series of 1-methyl-3,5-diphenyl4,5-dihydro-1H-pyrazoles, and evaluated for their inhibitory efficacy towards the two hMAO isoforms. Most of the derivatives were found to be potent and selective hMAO-B inhibitors. In particular, derivative 51 showed greater hMAO$B$ affinity than selective inhibitor selegiline coupled with high selectivity index $(\mathrm{SI}=145)$. [43]

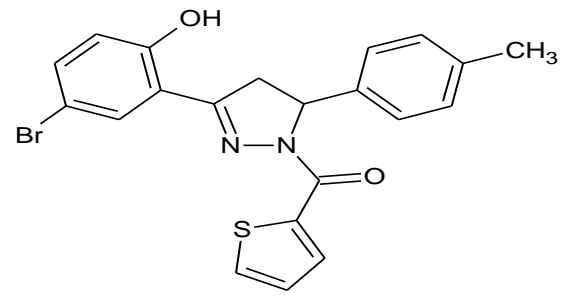

47

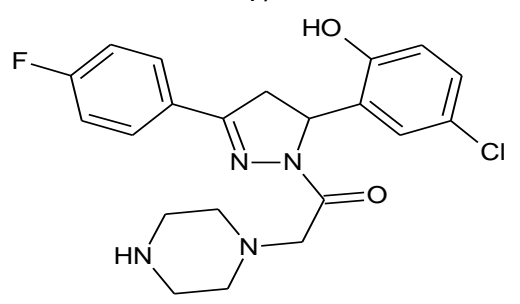

48<smiles>CC1=NN(C(=O)CN2CCNCC2)C(c2cc(Br)cc(Br)c2O)C1</smiles>

49

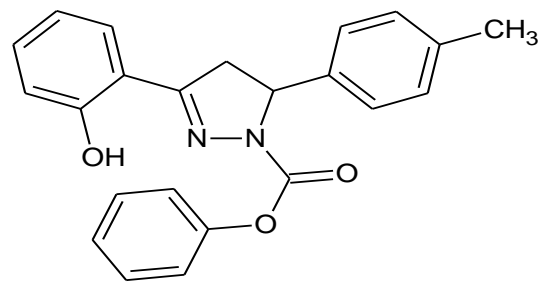

50<smiles>Cc1ccc(C2CC(c3ccccc3)=NN2C)cc1</smiles>

\section{Antitubercular activity}

R.C. Khunt et al synthesized a series of N-phenyl-3-(4fluorophenyl)-4-substituted pyrazoles 52 and tested for antimycobacterial activity in vitro against Mycobacterium tuberculosis H37Rv strain using the BACTEC 460 radiometric system. [44] Sharad C. Karad et al synthesized a novel series of fluoro substituted pyrazolylpyrazolines 53 was in good to excellent yield from pyrazole chalcones and substituted phenyl hydrazine hydrochlorides under microwave irradiation. The newly synthesized compounds were screened for their preliminary in vitro antibacterial activity against a panel of pathogenic strains of bacteria and fungi, antituberculosis activity against Mycobacterium tuberculosis H37Rv. Some of the compounds showed good antitubercular activity.[45] Mohamed Jawed Ahsan et al reported a series of 4-dihydro$3 \mathrm{H}$-indeno[1,2-c]pyrazole-2-carboxamide/carbothioamide analogues and evaluated for antitubercular activity by two fold serial dilution technique. All the newly synthesized compounds showed low to high inhibitory activities against Mycobacterium tuberculosis $\mathrm{H} 37 \mathrm{Rv}$ and INH resistant $\mathrm{M}$. tuberculosis. The compound 3-(4-fluorophenyl)- 6,7dimethoxy-3a,4-dihydro-3H-indeno[1,2-c]pyrazole-2-

carbothioamide 54 was found to be the most promising compound active against $\mathrm{M}$. tuberculosis $\mathrm{H} 37 \mathrm{Rv}$ and isoniazid resistant $M$. tuberculosis with minimum inhibitory concentration $3.12 \mu \mathrm{M}$ and $6.25 \mu \mathrm{M}$, respectively.[46] 
Indo Global Journal of Pharmaceutical Sciences, 2016; 6(1): 1-13

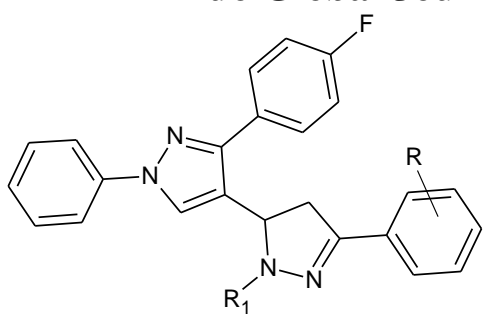

52

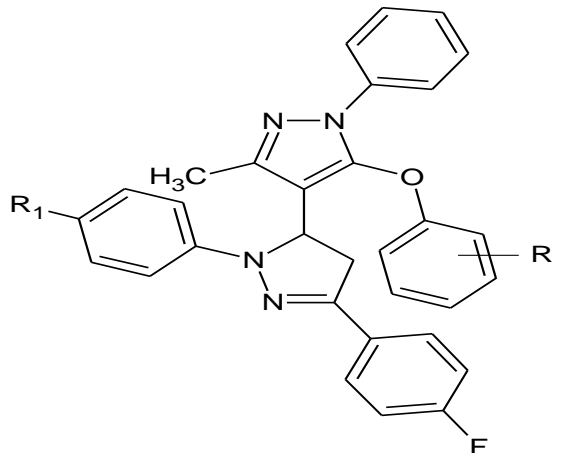

53<smiles>COc1cc2c(cc1OC)C1=NN(C(N)=S)C(c3ccc(F)cc3)C1C2</smiles>

54

\section{Antimicrobial activity}

Bakr F. Abdel-Wahab et al synthesized New pyrazolyl-1,2,3triazoles and 1,2,3-triazol-4-yl-pyrazolylthiazoles through multistep reactions using 1-tolylyl-4-acetyl-5-methyl-1,2,3triazole as a precursor. The newly synthesized compounds were evaluated for their antimicrobial activities and also their minimum inhibitory concentration (MIC) against most of test organisms was performed. Amongst the tested compounds 55 and 56 displayed excellent antimicrobial activity. [47] Mohmmad Younus Wani et al reported a series of pyrazoline derivatives by cyclization of chalcones with 2-[5-(4methoxyphenyl)-1H-tetrazol-1-yl]acetohydrazide under basic conditions and were screened in vitro, to find out effect on the growth of HM1: IMSS strain of Entamoeba histolytica. However compound 57 showed most promising results with $\mathrm{IC}_{50}-0.86 \mathrm{mM}$ which is half of the metronidazole, the standard drug used for protozoal infection. Cell viability test in human hepatocellular carcinoma cell line (HepG2) revealed non-toxic nature of new synthesized compounds. Safety index calculations prevailed compound 57 as highly antiamoebic and least cytotoxic (S.I. >116.28), almost twice than metronidazole. [48]
Novel compounds with antibacterial properties, pyrazoline derivatives were synthesized by Mamta Rani et al and was evaluated against two Gram-positive and two Gram-negative bacteria Aeromonas hydrophila, Yersinia enterocolitica, Listeria monocytogenes, and Staphylococcus aureus by microdilution method and then the minimum inhibitory concentration (MIC) of compounds were determined. The results Revealed that compounds (5R)-5-(furan-2-yl)-1phenyl-3-[2-(benzyloxy)phenyl]-4, 5-dihydro-1Hpyrazole, 58 and (5R)-5-(furan-2-yl)-1-phenyl-3-[2-(naphthalen-2ylmethoxy prop-2-en-1-yloxy) phenyl]-4,5-dihydro-1Hpyrazole 59 showed most promising antibacterial activities as compared to Gentamicin and Tetracycline. [49] Pankaj B. Miniyar et al synthesized a novel series of 2-Chloroquinoline nucleus clubbed with the pyrazole ring and screened for antibacterial and antifungal activity. The results obtained were promising against both bacterial and fungal strains. Among the series, compound 60 was found moderately active against Aspergillus fumigatus, Penicillium notatum and Bacillus subtilis having MIC 48,46 and $44 \mu \mathrm{g} / \mathrm{ml}$, respectively whereas compound 61 was found active against $P$. notatum, $B$. subtilis and Escherichia coli having MIC 57, 54 and $43 \mu \mathrm{g} / \mathrm{ml}$, respectively as compared to standard.

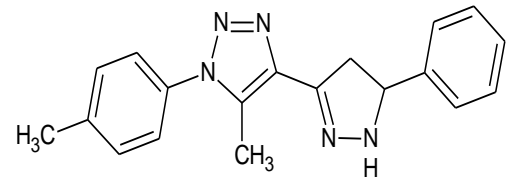

55

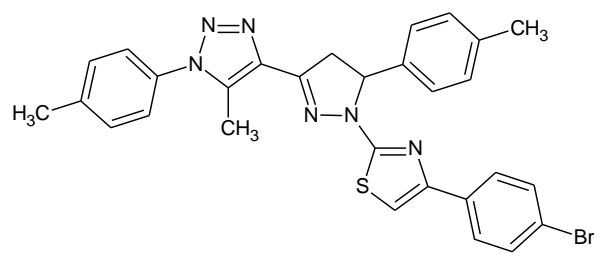

56

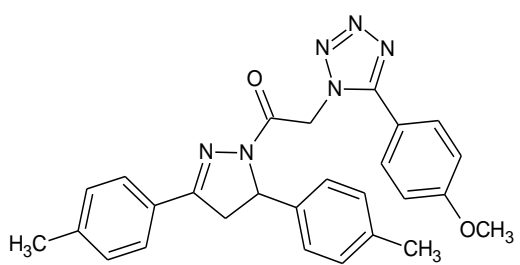

57

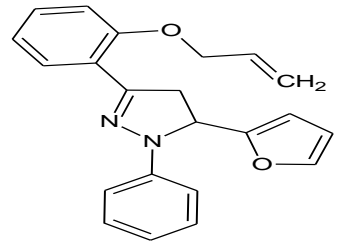

58 
Indo Global Journal of Pharmaceutical Sciences, 2016; 6(1): 1-13

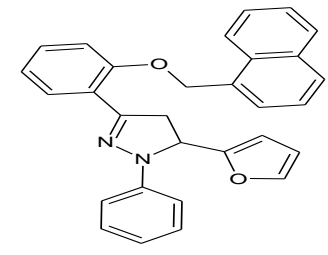

59

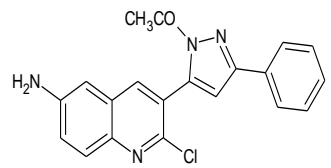

60

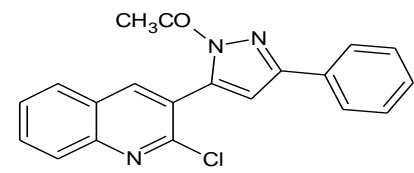

61

potential antiproliferative agents", Bioorganic \& Medicinal Chemistry Letters 24 (2014) 1685-1691.

8. Kamilia M. Amin, Sahar M. Abou-Seri, Fadi M. Awadallah, Amal A.M. Eissa, Ghaneya S. Hassan, Mohamed M. Abdulla, "Synthesis and anticancer activity of some 8-substituted-7methoxy- $2 \mathrm{H}$-chromen-2-one derivatives toward hepatocellular carcinoma HepG2 cells", European Journal of Medicinal Chemistry 90 (2015) 221-231.

9. Ke-Ming Qiu, Hai-Hong Wang, Li-Ming Wang, Yin Luo, XianHui Yang, Xiao-Ming Wang, Hai-Liang Zhu, "Design, synthesis and biological evaluation of pyrazolyl-thiazolinone derivatives as potential EGFR and HER-2 kinase inhibitors, Bioorganic \& Medicinal Chemistry 20 (2012) 2010-2018.

10. Fadi M. Awadallah, Gary A. Piazza, Bernard D. Gary, Adam B. Keeton, Joshua C. Canzoneri, "Synthesis of some dihydropyrimidine-based compounds bearing pyrazoline moiety and evaluation of their antiproliferative activity", European Journal of Medicinal Chemistry 70 (2013) 273-279.

11. Peng-Cheng Lv, Dong-Dong Li, Qing-Shan Li, Xiang Lu, ZhuPing Xiao, Hai-Liang Zhu, "Synthesis, molecular docking and evaluation of thiazolyl-pyrazoline derivatives as EGFR TK inhibitors and potential anticancer agents", Bioorganic \& Medicinal Chemistry Letters 21 (2011) 5374-5377.

12. Violeta Markovic, Slavica Eric, Tatjana Stanojkovic, Nevenka Gligorijevic, Sandra Arand-elovic, Nina Todorovic, Snežana Trifunovic, Nedeljko Manojlovic, Ratomir Jelic, Milan D. Joksovic, "Antiproliferative activity and QSAR studies of a series of new 4-aminomethylidene derivatives of some pyrazol5-ones, Bioorganic \& Medicinal Chemistry Letters 21 (2011) 4416-4421.

13. Nitin Kumar, Ankita Bhatnagar, Rupesh Dudhe, "Synthesis of 3-(4, 5-dihydro-1-phenyl-5-substituted phenyl-1H-pyrazol-3-yl)$2 \mathrm{H}$-chromen-2-one derivatives and evaluation of their anticancer activity", Arabian Journal of Chemistry (2013), Article in Press.

14. Kamilia M. Amin, Amal A.M. Eissa, Sahar M. Abou-Seri*, Fadi M. Awadallah, Ghaneya S. Hassan, Synthesis and biological evaluation of novel coumarinepyrazoline hybrids endowed with phenylsulfonyl moiety as antitumor agents, European Journal of Medicinal Chemistry 60 (2013) 187-198.

15. Pravin O. Patil, Sanjay B. Bari, "Synthesis, characterization and screening for antidepressant and anticonvulsant activity of 4,5dihydropyrazole bearing indole derivatives", Arabian Journal of Chemistry (2013), Article in Press.

16. Nagihan Beyhan, Bedia Kocyigit-Kaymakcioglu, Salih Gumru, Feyza Aricioglu, "Synthesis and anticonvulsant activity of some 2-pyrazolines derived from chalcones", Arabian Journal of Chemistry (2013), Article in Press.

17. Nikhil D. Amnerkar, Kishore P. Bhusari, "Synthesis, anticonvulsant activity and 3D-QSAR study of some prop-2eneamido and 1-acetyl-pyrazolin derivatives of aminobenzothiazole", European Journal of Medicinal Chemistry 45 (2010) 149-159.

18. Zafer Asım Kaplancıklı, Ahmet Özdemir, Gülhan TuranZitouni, Mehlika Dilek Altıntop, Özgür Devrim Can, "New pyrazoline derivatives and their antidepressant activity", European Journal of Medicinal Chemistry 45 (2010) 4383-4387.

19. Vincent Gembus, Christophe Furman, Régis Millet, Roxane Mansouri, Philippe Chavatte, Vincent Levacher, Jean-François Brière, "Scaffold hopping strategy toward original pyrazolines as selective CB2 receptor Ligands", European Journal of Medicinal Chemistry 58 (2012) 396-404.

20. Jos H. M. Lange, Martina A. W. van der Neut, Arnold P. den Hartog, Henri C. Wals, Jan Hoogendoorn, Herman H. van 


\section{Indo Global Journal of Pharmaceutical Sciences, 2016; 6(1): 1-13}

Stuivenberg, Bernard J. van Vliet, Chris G. Kruse, "Synthesis, SAR and intramolecular hydrogen bonding pattern of 1,3,5trisubstituted 4,5-dihydropyrazoles as potent cannabinoid CB1 receptor antagonists", Bioorganic \& Medicinal Chemistry Letters 20 (2010) 1752-1757.

21. Minmin Yu, Hui Yang, Kaihua Wu, Ying Ji, Lili Ju, Xiaoyuan Lu, "Novel pyrazoline derivatives as bi-inhibitor of COX-2 and B-Raf in treating cervical carcinoma", Bioorganic \& Medicinal Chemistry 22 (2014) 4109-4118.

22. Ke-Ming Qiu, Ru Yan, Man Xing, Hai-Hong Wang, Hong-En Cui, Hai-Bin Gong, Hai-Liang Zhu, "Synthesis, biological evaluation and molecular modeling of dihydro-pyrazolylthiazolinone derivatives as potential COX-2 inhibitors", Bioorganic \& Medicinal Chemistry 20 (2012) 6648-6654.

23. Rossella Fioravanti, Adriana Bolasco, Fedele Manna, Francesca Rossi, Francisco Orallo, Francesco Ortuso, Stefano Alcaro, Roberto Cirilli, "Synthesis and biological evaluation of Nsubstituted-3,5-diphenyl-2-pyrazoline derivatives as cyclooxygenase (COX-2) inhibitors", European Journal of Medicinal Chemistry 45 (2010) 6135-6138.

24. Habibullah Khalilullah, Shamshir Khan, Mohamed Jawed Ahsan, Bahar Ahmed, "Synthesis and antihepatotoxic activity of 5-(2,3-dihydro-1, 4-benzodioxane-6-yl)-3-substituted-phenyl4,5-dihydro-1H-pyrazole derivatives", Bioorganic \& Medicinal Chemistry Letters 21 (2011) 7251-7254.

25. Habibullah Khalilullah, Shamshir Khan, Mohamed Jawed Ahsan, Bahar Ahmed, "Synthesis and antihepatotoxic activity of 5-(2,3-dihydro-1,4-benzodioxane-6-yl)-3-substituted-phenyl4,5-dihydro-1H-pyrazole derivatives", Bioorganic \& Medicinal Chemistry Letters 21 (2011) 7251-7254.

26. Manisha R. Bhosle, Amarsinh R. Deshmukh, Savita Pal, Arvind K. Srivastava, Ramrao A. Mane, "Synthesis of new thiazolylmethoxyphenyl pyrimidines and antihyperglycemic evaluation of the pyrimidines, analogues isoxazolines and pyrazolines", Bioorganic \& Medicinal Chemistry Letters 25 (2015) 2442-2446.

27. Syed Ovais, H. Pushpalatha, G. Bhanuprakash Reddy, Pooja Rathore, Rafia Bashir, Shafiya Yaseen, Alhamza Dheyaa, Raed Yaseen, Omprakash Tanwar, Mymoona Akthar, Mohammed Samim a, Kalim Javed, "Synthesis and biological evaluation of some new pyrazoline substituted benzenesulfonylurea/thiourea derivatives as anti-hyperglycaemic agents and aldose reductase inhibitors", European Journal of Medicinal Chemistry 80 (2014) 209-217.

28. Chetna Kharbanda, Mohammad Sarwar Alam, Hinna Hamid, Kalim Javed, Syed Shafi, Yakub Ali ,Perwez Alam, M. A. Q. Pasha, Abhijeet Dhulap, Sameena Bano, Syed Nazreen, Saqlain Haider, "Novel benzenesulfonylureas containing thiophenylpyrazoline moiety as potential antidiabetic and anticancer agents", Bioorganic \& Medicinal Chemistry Letters 24 (2014) 5298-5303.

29. Shivapura Viveka, Dinesha, Prasanna Shama, Gundibasappa Karikannar Nagaraja, Shuvankar Ballav, Savita Kerkar, "Design and synthesis of some new pyrazolyl-pyrazolines as potential anti-inflammatory, analgesic and antibacterial agents", European Journal of Medicinal Chemistry 101 (2015) 442-451.

30. Adithya Adhikari, Balakrishna Kalluraya, Kizhakke Veedu Sujith, Kuluvar Gouthamchandra, Ravikumar Jairam, Riaz Mahmood, Ravish Sankolli, "Synthesis, characterization and pharmacological study of 4,5-dihydropyrazolines carrying pyrimidine moiety", European Journal of Medicinal Chemistry 55 (2012) 467-474.
31. Jiqiang He, Liang Ma, Zhe Wei, Jun Zhu, Fei Peng, Mingfeng Shao, Lei Lei, Lin He, Minghai Tang, Linhong He, Yuzhe Wu, Lijuan Chen, "Synthesis and biological evaluation of novel pyrazoline derivatives as potent anti-inflammatory agents", Bioorganic \& Medicinal Chemistry Letters 25 (2015) 24292433.

32. Chetna Kharbanda, Mohammad Sarwar Alam, Hinna Hamid, Kalim Javed, Sameena Bano, Abhijeet Dhulap, Yakub Ali, Syed Nazreen, Saqlain Haider, "Synthesis and evaluation of pyrazolines bearing benzothiazole as anti-inflammatory agents", Bioorganic \& Medicinal Chemistry 22 (2014) 5804-5812.

33. Babasaheb P. Bandgar, Laxman K. Adsul, Hemant V. Chavan, Shivkumar S. Jalde, Sadan and N. Shringare, Rafique Shaikh, Rohan J. Meshram, Rajesh N. Gacche, Vijay Masand, "Synthesis, biological evaluation, and docking studies of 3(substituted)-aryl-5-(9-methyl-3-carbazole)-1H-2-pyrazolines as potent anti-inflammatory and antioxidant agents", Bioorganic \& Medicinal Chemistry Letters 22 (2012) 5839-5844.

34. Magda A.-A. El-Sayed, Naglaa I. Abdel-Aziz, Alaa A.-M. Abdel-Aziz, Adel S. El-Azab, Kamal E.H. ElTahir, "Synthesis, biological evaluation and molecular modeling study of pyrazole and pyrazoline derivatives as selective COX-2 inhibitors and anti-inflammatory agents. Part 2", Bioorganic \& Medicinal Chemistry 20 (2012) 3306-3316.

35. Ranjana Aggarwal, Sunil Kumar, Pawan Kaushik, Dhirender Kaushik, Girish Kumar Gupta, "Synthesis and pharmacological evaluation of some novel 2-(5-hydroxy-5-trifluoromethyl-4,5dihydropyrazol-1-yl)- 4-(coumarin-3-yl)thiazoles", European Journal of Medicinal Chemistry 62 (2013) 508-514.

36. Badri Narayan Acharya, Deepika Saraswat, Mugdha Tiwari, Asish Kumar Shrivastava, Ramarao Ghorpade, Saroj Bapna, Mahabir Parshad Kaushik," Synthesis and antimalarial evaluation of 1, 3, 5-trisubstituted pyrazolines", European Journal of Medicinal Chemistry 45 (2010) 430-438.

37. Akshay Kumar, Bhat G. Varadaraj, Rajeev K. Singla, “ Synthesis and evaluation of antioxidant activity of novel 3,5disubstituted-2-pyrazolines", Bulletin of Faculty of Pharmacy, Cairo University (2013) 51, 167-173.

38. Helio G. Bonacorso, Susiane Cavinatto, Patrick T. Campos, Liliane M.F. Porte, Jussara Navarini, Gisele R. Paim, Marcos A.P. Martins, Nilo Zanatta, Caroline Z. Stuker, "New trifluoromethyl-containing alkyl(aryl/heteroaryl)-4,5(E)-N0-arylidene-[3yl]carbohydrazides: Synthesis, crystal structure and antimicrobial/antioxidant activity", Journal of Fluorine Chemistry 135 (2012) 303-314.

39. Adithya Adhikari, Balakrishna Kalluraya, Kizhakke Veedu Sujith, Kuluvar Gouthamchandra, Ravikumar Jairam, Riaz Mahmood, Ravish Sankolli, "Synthesis, characterization and pharmacological study of 4,5-dihydropyrazolines carrying pyrimidine moiety", European Journal of Medicinal Chemistry 55 (2012) 467-474.

40. Begum Evranos-Aksoz, Samiye Yabanog־lu-Ciftci, Gulberk Ucar, Kemal Yelekci, Rahmiye Ertan, "Synthesis of some novel hydrazone and 2-pyrazoline derivatives: Monoamine oxidase inhibitory activities and docking studies", Bioorganic \& Medicinal Chemistry Letters 24 (2014) 3278-3284.

41. Xu Tong, Rui Chen, Tong-Tian Zhang, Yan Han, Wen-Jian Tang, Xin-Hua Liu, "Design and synthesis of novel 2pyrazoline-1-ethanone derivatives as selective MAO inhibitors", Bioorganic \& Medicinal Chemistry 23 (2015) 515-525.

42. B. Vishnu Nayak, S. Ciftci-Yabanoglu, Surender Singh Jadav, Monika Jagrat, Barij N. Sinha, G. Ucar, Venkatesan 
Indo Global Journal of Pharmaceutical Sciences, 2016; 6(1): 1-13

Jayaprakash, "Monoamine oxidase inhibitory activity of 3,5biaryl-4,5-dihydro-1Hpyrazole- 1-carboxylate derivatives", European Journal of Medicinal Chemistry 69 (2013) 762-767.

43. Rossella Fioravanti, Nicoletta Desideri, Mariangela Biava, Luca Proietti Monaco, Laura Grammatica, Matilde Yáñez, "Design, synthesis, and in vitro hMAO-B inhibitory evaluation of some 1methyl-3,5-diphenyl-4,5-dihydro-1H-pyrazoles", Bioorganic \& Medicinal Chemistry Letters 23 (2013) 5128-5130.

44. R.C. Khunt, V.M. Khedkar, R.S. Chawda, N.A. Chauhan, A.R. Parikh, E.C. Coutinho, "Synthesis, antitubercular evaluation and 3D-QSAR study of N-phenyl-3-(4-fluorophenyl)-4-substituted pyrazole derivatives", Bioorganic \& Medicinal Chemistry Letters 22 (2012) 666-678.

45. Sharad C. Karad, Vishal B. Purohit, Dipak K. Raval, "Design, synthesis and characterization of fluoro substituted novel pyrazolylpyrazolines scaffold and their pharmacological screening”, European Journal of Medicinal Chemistry 84 (2014) 51-58.

46. Mohamed Jawed Ahsan, Jeyabalan Govinda Samy, Savita Soni, Naresh Jain, Lalit Kumar, Lalit K. Sharma, Hemant Yadav, Lokesh Saini, Rajput Gopal Kalyansing, Narendra S. Devenda, Ravindra Prasad, Chandra Bhushan Jain, "Discovery of novel antitubercular 3a,4-dihydro-3H-indeno[1,2-c]pyrazole-2carboxamide/carbothioamide analogues", Bioorganic \& Medicinal Chemistry Letters 21 (2011) 5259-5261.

47. Bakr F. Abdel-Wahab, Ehab Abdel-Latif, Hanan A. Mohamed, Ghada E.A. Awad, "Design and synthesis of new 4-pyrazolin-3yl-1,2,3-triazoles and 1,2,3-triazol-4-yl-pyrazolin-1-ylthiazoles as potential antimicrobial agents", European Journal of Medicinal Chemistry 52 (2012) 263-268.

48. Mohmmad Younus Wani, Abdul Roouf Bhat, Amir Azam, Dae Hyung Lee, Inho Choi, Fareeda Athar, "Synthesis and in vitro evaluation of novel tetrazole embedded 1,3,5-trisubstituted pyrazoline derivatives as Entamoeba histolytica growth inhibitors", European Journal of Medicinal Chemistry 54 (2012) 845-854.

49. Mamta Rani, Mohamad Yusuf, Salman Ahmad Khan, P.P. Sahota, G. Pandove, "Synthesis, studies and in-vitro antibacterial activity of N-substituted 5-(furan-2-yl)-phenyl pyrazolines", Arabian Journal of Chemistry (2015) 8, 174-180.

50. Pankaj B. Miniyar, Mahesh A. Barmade, Anand A. Mahajan, "Synthesis and biological evaluation of 1-(5-(2-chloroquinolin3-yl)-3-phenyl-1H-pyrazol-1-yl) ethanone derivatives as potential antimicrobial Agents", Journal of Saudi Chemical Society (2014), Article in Press.

Indo Global Journal of Pharmaceutical Sciences( ISSN 22491023 ; CODEN-IGJPAI; NLM ID: 101610675) indexed and abstracted in EMBASE(Elsevier), SCIRUS(Elsevier),CABI, CAB Abstracts, Chemical Abstract Services(CAS), American Chemical Society(ACS), Index Copernicus, EBSCO, DOAJ, Google Scholar and many more. For further details, visit 